\title{
The Cost to Successfully Apply for Level 3 Medical Home Recognition
}

\author{
Jacqueline R. Halladay, MD, MPH, Katbleen Mottus, PhD, Kristin Reiter, PhD, \\ C. Madeline Mitchell, MURP, Katrina E. Donabue, MD, MPH, \\ Wilson M. Gabbard, MBA-HSM, and Kimberly Gush, MD, PhD
}

Background: The National Committee for Quality Assurance patient-centered medical home recognition program provides practices an opportunity to implement medical home activities. Understanding the costs to apply for recognition may enable practices to plan their work.

Methods: Practice coaches identified 5 exemplar practices ( 3 pediatric and 2 family medicine practices) that received level 3 recognition. This analysis focuses on 4 that received recognition in 2011. Clinical, informatics, and administrative staff participated in 2- to 3-hour interviews. We determined the time required to develop, implement, and maintain required activities. We categorized costs as (1) nonpersonnel, (2) developmental, (3) those used to implement activities, (4) those used to maintain activities, (5) those to document the work, and (6) consultant costs. Only incremental costs were included and are presented as costs per full-time equivalent (pFTE) provider.

Results: Practice size ranged from 2.5 to 10.5 pFTE providers, and payer mixes ranged from $7 \%$ to $43 \%$ Medicaid. There was variation in the distribution of costs by activity by practice, but the costs to apply were remarkably similar (\$11,453-15,977 pFTE provider).

Conclusion: The costs to apply for 2011 recognition were noteworthy. Work to enhance care coordination and close loops were highly valued. Financial incentives were key motivators. Future efforts to minimize the burden of low-value activities could benefit practices. (J Am Board Fam Med 2016;29:69-77.)

Keywords: Cost Control, Medical Home, Patient-centered Care, Practice Management

Great efforts are underway to move the US primary care system toward delivering high-quality, timely, patient-centered, and affordable care. One such

This article was externally peer reviewed.

Submitted 7 July 2015; revised 18 August 2015; accepted 24 August 2015.

From the Department of Family Medicine (JRH, KED), Cecil G. Sheps Center for Health Services Research (JRH, KED, KM, CMM), the Department of Health Policy and Management, Gillings School of Global Public Health (KR), University of North Carolina at Chapel Hill, Chapel Hill; the University of North Carolina Physicians Network, Morrisville (WMG); and Village Pediatrics of Chapel Hill (KG).

Funding: This work was supported by the Agency for Healthcare Research and Quality (R031 R03 HS022629-01). Conflict of interest: none declared.

Disclaimer: The authors of this report are responsible for its content. Statements in this article should not be construed as endorsements by the Agency for Healthcare Research and Quality or the U.S. Department of Health and Human Services.

Corresponding author: Jacqueline R. Halladay, MD, MPH, Department of Family Medicine, Cecil G. Sheps Center for Health Services Research, University of North Carolina at Chapel Hill, 590 Manning Dr., Chapel Hill, NC 27599 (E-mail: Jacqueline_halladay@med.unc.edu). effort has been to encourage practices to adopt, implement, and sustain the strategies identified in the patient-centered medical home $(\mathrm{PCMH})$ model. ${ }^{1}$ Under the PCMH model, care team members work collaboratively to provide coordinated, proactive, and accessible care. ${ }^{2}$ This requires that practices have the resources and infrastructure to offer preventive, disease, and care management services $^{3,4}$; have clinical staff readily available to address patient needs ${ }^{5-7}$; and be able to connect patients with community resources. ${ }^{8-12}$ Although adopting the PCMH model holds promise as an improvement strategy, it remains to be seen whether practices can successfully transform to and sustain this new model of care. ${ }^{1}$ Lessons from the National Demonstration Project suggest that achieving PCMH recognition is a long, slow, and resource-intensive process, even in particularly motivated practices. ${ }^{13,14}$

Because of the level of investment required, one strategy for encouraging widespread adoption of 
the PCMH model has been to offer practices formal recognition as a PCMH by the National Committee for Quality Assurance (NCQA). ${ }^{15}$ This recognition allows practices to publicly promote their status, which may bolster their reputation in the community and, in some cases, garner enhanced reimbursements from payers. To apply for recognition, however, practice staff and administrators need to understand the PCMH standards and application requirements. They may also need to develop and implement new policies and engage in multiple activities that draw on human and other resources.

Several studies have attempted to identify the costs associated with transformation to a PCMH; however, we were unable to find any that measured the practice-level cost of developing and submitting a formal application to the NCQA. ${ }^{16,17}$ This study attempts to fill that gap by using an activitybased approach to identify the costs incurred by primary care practices in applying for and being recognized by the NCQA as a level 3 PCMH.

\section{Methods}

\section{Practice Recruitment}

Following an approach developed in a previous study, ${ }^{18}$ we consulted with practice coaches from the North Carolina Area Health Education Center's Practice Support Program to identify primary care practices that had achieved level $3 \mathrm{PCMH}$ recognition, defined as a score of 85 to 100 points and receiving credit for all 6 must-pass elements. We asked coaches to recommend 5 exemplar practices that used internal clinical and administrative staff members to complete the majority of the work required to apply for PCMH recognition (vs relying on the work of people external to the practice). We invited 3 pediatric and 2 family medicine practices, all of which agreed to participate.

\section{Data Collection}

Starting with instruments used in prior studies of practice-level costs of quality improvement, ${ }^{16,19}$ we developed an in-person survey tool to collect the costs of completing the activities listed in the 2011 PCMH "Survey Tool" application. ${ }^{20}$ Our tool followed the structure of the 2011 standards application, in which specific activities, called "factors," are grouped into "elements," which are further assembled into 6 overarching PCMH "standards."
Before primary data collection, we contacted the leaders of each practice to identify all practice members who worked on the PCMH application and arranged for group key informant interviews. We also examined completed PCMH applications and NCQA scoring sheets to tailor our interviews.

Between March and November 2014 we conducted on-site, in-person interviews during which informants provided estimates of the time (in minutes) required to complete each factor. Interviews took 2 to 3 hours to complete and included practice administrators, informatics staff, and office staff representing numerous organizational roles.

We also collected information about nonpersonnel expenses such as application fees, software purchases, or website changes that were needed to fulfill the requirements. Because our focus was on incremental costs, we included only new information technology costs that were incurred specifically to meet PCMH application requirements. For practice organizations that may have submitted an application for $>1$ practice, we used expenses attributed to the single practice. Finally, we asked practices to identify high-value activities, defined as those deemed to improve the quality and experience of care.

After piloting the data collection tool in the first practice, we recognized the need to categorize personnel costs further, beyond the factor-elementstandard structure. Thus, for the subsequent interviews, we also obtained time estimates relating to (1) development phase costs (one-time staffing costs required to develop new processes); (2) implementation phase costs (staffing costs required to implement new processes); (3) maintenance phase costs (staffing costs to maintain new activities after the application was submitted); (4) costs specific to preparing documents for the application submission; and (5) costs to support an external practice coach or consultant. Table 1 describes our final cost categories and includes examples. Costs for the development and implementation phases, as well as document preparation and external assistance, were accrued from the decision-to-apply date to the application submission date. Maintenance costs were annualized and included costs that applied to activities that continued after the applications were submitted and were still ongoing at the time of the respective interviews.

Two investigators and one research assistant attended each interview; all recorded reported time 
Table 1. Patient-centered Medical Home Cost Categories: Making Practice Changes and Applying to the National Committee for Quality Assurance for Patient-centered Medical Home Recognition

\begin{tabular}{|c|c|c|}
\hline Category & Definition & Examples \\
\hline Nonpersonnel costs & $\begin{array}{l}\text { Expenses to cover supplies and other fees not } \\
\text { related to staff time }\end{array}$ & $\begin{array}{l}\text { Application fees, website updates, software } \\
\text { purchases (eg, Adobe Acrobat, patient } \\
\text { satisfaction survey software) }\end{array}$ \\
\hline Development phase & $\begin{array}{l}\text { Staff time required to develop new PCMH } \\
\text { processes }\end{array}$ & $\begin{array}{l}\text { Developing new report in EHR, creating } \\
\text { or writing policies or job descriptions, } \\
\text { creating new documents or procedures }\end{array}$ \\
\hline Implementation phase & $\begin{array}{l}\text { Staff time required for implementing new } \\
\text { processes }\end{array}$ & $\begin{array}{l}\text { Staff training, incorporating new process } \\
\text { such as previsit prevention planning; } \\
\text { medication reconciliation; standing } \\
\text { orders for flu vaccines, labs, etc.; quality } \\
\text { improvement meetings; conducting } \\
\text { patient satisfaction surveys; providing } \\
\text { enhanced or new care management } \\
\text { services }\end{array}$ \\
\hline Maintenance phase & $\begin{array}{l}\text { Staff time required to maintain new activities } \\
\text { after application submitted }\end{array}$ & $\begin{array}{l}\text { Logging after hours patient calls, care } \\
\text { management visits, quality improvement } \\
\text { meetings }\end{array}$ \\
\hline Application document preparation & $\begin{array}{l}\text { Time required to create application } \\
\text { documents such as screenshots }\end{array}$ & $\begin{array}{l}\text { Taking screenshots to provide evidence of } \\
\text { activities, redacting patient health } \\
\text { information from examples, annotating } \\
\text { to demonstrate compliance with } \\
\text { requirements }\end{array}$ \\
\hline External consultant & $\begin{array}{l}\text { Services provided by staff not on the practice } \\
\text { payroll }\end{array}$ & $\begin{array}{l}\text { Consultant time to complete chart review } \\
\text { workbook, coach time guiding practice } \\
\text { through the NCQA application process }\end{array}$ \\
\hline
\end{tabular}

EHR, electronic health record; NCQA, National Committee for Quality Assurance; PCMH, patient-centered medical home.

estimates by role and cost category. Following the first 2 interviews, 2 different team members separately entered the information into the data collection tool, then all 3 team members met to discuss the process and to reach consensus on time allocations by role and category. Once the team was comfortable with the process, one individual would enter the data, but the team continued to meet to discuss uncertainties and to reach consensus on final time allocations. The interviews were digitally recorded and transcribed, and the final data were cross-checked with these resources to ensure accuracy.

\section{Cost Calculations}

To calculate cost estimates, we converted time estimates from minutes to hours and multiplied these estimates by 2012 mean US hourly salaries (per the National Compensation Survey), ${ }^{21}$ because this is the year that the work commenced first among the study practices. In cases where the roles of individuals did not match roles as defined in this national data source, we used actual salaries (this occurred primarily for personnel with both clinical degrees and significant informatics expertise). Consistent with cost reports provided by the Medical Group Management Association, ${ }^{22}$ these cost estimates were converted to cost per full-time equivalent (FTE) provider; providers were defined as physician assistants (PAs), doctors of osteopathy (DOs), doctors of medicine (MDs), or nurse practitioners (NPs).

This research was submitted to the nonmedical institutional review board at the University of North Carolina at Chapel Hill and was deemed exempt.

\section{Results}

Five practices were included in the study; 1 practice received PCMH recognition under the 2008 NCQA criteria, whereas the others were recognized under 2011 criteria. Because of notable differences in the required activities, the results presented in this article are limited to the 4 practices using 2011 criteria. Practice characteristics are presented in Table 2. Three of the practices were pediatric clinics and 1 was a family medicine clinic. Two of the pediatric practices ( 2 and 3 ) were from the coastal region of North Carolina, and the fam- 
Table 2. Practice Demographics for 4 North Carolina Primary Care Practices Receiving Patient-centered Medical Home Recognition in 2013 or 2014 via the National Committee for Quality Assurance 2011 Patient-centered Medical Home Standards*

\begin{tabular}{lcccccccc}
\hline & $\begin{array}{c}\text { Provider } \\
\text { FTEs }^{\dagger}\end{array}$ & $\begin{array}{c}\text { Patient visits/ } \\
\text { year (n) }\end{array}$ & $\begin{array}{c}\text { Medicaid } \\
(\%)\end{array}$ & $\begin{array}{c}\text { Uninsured } \\
(\%)\end{array}$ & $\begin{array}{c}\text { Commercial } \\
\text { Insurance (\%) }\end{array}$ & $\begin{array}{c}\text { Nonwhite } \\
\text { Patients (\%) }\end{array}$ & $\begin{array}{c}\text { Date of PCMH } \\
\text { Level 3 } \\
\text { Recognition }\end{array}$ & $\begin{array}{c}\text { Study Interview } \\
\text { Dates }\end{array}$ \\
\hline 1 (Pediatrics) & 2.5 & 4,477 & 7 & 5 & 88 & 21 & December 2013 & March 2014 \\
2 (Pediatrics) & 10.5 & 39,172 & 43 & 0.3 & 57 & 53 & January 2014 & May 2014 \\
3 (Pediatrics) & 3.5 & 12,813 & 30 & 5 & 65 & 19 & July 2014 & August 2014 \\
4 (Family & 4 & 15,094 & 15 & 10 & 55 & 35 & July 2014 & November \\
medicine) & & & & & & & & 2014 \\
\hline
\end{tabular}

*Patient-centered medical home (PCMH) 2011 standards were released in the spring of 2011; the 2014 standards, in the spring of 2014. Depending on a practice's start date and initial PCMH level attained, practices could be working on 2011 standards up until 2018.

${ }^{\dagger}$ Includes medical doctors, doctors of osteopathy, nurse practitioners, and physician assistants.

FTE, full-time equivalent.

ily practice and remaining pediatric practice ( 1 and 4) were from the central region. Practices 2 and 4 were part of larger practice organizations, whereas practices 1 and 3 were independent practices. Approximately $55 \%$ to $88 \%$ of patients were covered by commercial/private health insurance, whereas the percentage of patients with Medicaid ranged from $7 \%$ to $43 \%$.

The costs per provider of applying for PCMH recognition are shown in Table 3 . These costs ranged from $\$ 11,453$ to $\$ 15,997$ per FTE provider and reflected the costs of new work required to implement key activities for PCMH recognition and to prepare the application. Interestingly, although the total costs per FTE provider were remarkably similar, there was substantial variation among the 4 practices in the activities that drove the costs. These differences are most likely related to the differences in patient populations (pediatric vs family medicine patients) and/or differences in the extent to which certain activities had already been developed in the respective settings. For example, the costs to provide enhanced care services were much higher in the family medicine practice compared with the pediatric practices. This is likely because of the difference in the burden of chronic disease among the adult versus the pediatric population. By contrast, the costs of developing new policies and processes were higher in the pediatric practices because many of these job descriptions and office policies needed to be created anew.

Table 3. Costs of Patient-centered Medical Home Recognition via 2011 Standards among 4 Practices

\begin{tabular}{|c|c|c|c|c|c|c|}
\hline \multirow[b]{2}{*}{ Practice } & \multicolumn{6}{|c|}{ Costs By Category $(\$)$} \\
\hline & $\begin{array}{l}\text { Nonstaff* } \\
\text { (Application } \\
\text { Fees, } \\
\text { Supplies) }\end{array}$ & $\begin{array}{l}\text { Development Phase* } \\
\text { (Creating New } \\
\text { Processes, Reports, } \\
\text { Policies) }\end{array}$ & $\begin{array}{c}\text { Implementation } \\
\text { Phase* } \\
\text { (Providing }^{*} \\
\text { Enhanced Care } \\
\text { Services }^{\dagger} \text { ) }\end{array}$ & $\begin{array}{l}\text { Application } \\
\text { Document } \\
\text { Prep** } \\
\text { (Screen } \\
\text { Shots) }\end{array}$ & $\begin{array}{l}\text { Total Costs } \\
\text { to Apply*§}\end{array}$ & $\begin{array}{l}\text { Maintenance Phase } \\
\text { (Ongoing Costs } \\
\text { for Staff and } \\
\text { Supplies), } \\
\text { Annualized }\end{array}$ \\
\hline 1 (Pediatrics) & 696 & 9,294 & 2,606 & 975 & 13,571 & 10,151 \\
\hline 2 (Pediatrics) & 419 & 7,249 & 3,649 & 137 & 11,453 & 7,789 \\
\hline 3 (Pediatrics) & 554 & 8,643 & 3,487 & 846 & 13,531 & 0 \\
\hline $\begin{array}{l}4 \text { (Family } \\
\text { medicine) }\end{array}$ & 131 & 3,275 & 12,269 & 303 & 15,977 & 23,494 \\
\hline
\end{tabular}

Costs are expressed as per full-time provider (nurse practitioner/physician assistant/DO/MD).

${ }^{*}$ Costs accrued from decision date to apply for patient-centered medical home status to application date. The time interval for the activities listed before the maintenance phase ranged from 9 to 18 months in this sample of practices.

${ }^{\dagger}$ Includes both new hires and enhanced activities and training for existing staff.

${ }^{\ddagger}$ Does not include staff time dedicated to uploading and sending application to the National Committee for Quality Assurance.

${ }^{\S}$ Does not include practice level consultation costs listed in Table 4. 
Another marked difference was in the cost to maintain activities. While all practices noted an intention to maintain certain activities beyond the application, practice 3 reported no incremental maintenance costs because they had previously developed a comprehensive asthma care management system during participation in a statewide quality improvement initiative.

One cost driver that was consistent across all practices was creating screenshots to document the practice's compliance with the factors. Interviewees from all 4 practices reported that each screen shot took between 15 and 30 minutes to complete, and each practice created anywhere from 78 to just over 100 of these documents. This included finding examples (eg, logs to capture after-hours consultations with patients, formal care agreements with referring providers); redacting the patient's name or other identifiers; annotating the documents to identify compliance with specific factors; and converting the documents back into a PDF. The total cost of preparing documents for the application ranged from $\$ 1,212$ to $\$ 2,961$ per practice; the difference was driven primarily by the number of screenshots and the salaries of the people doing this work.

While the costs of applying for PCMH recognition were consistent across practices on a perprovider basis, multiplying the cost per provider by the number of providers revealed wide variation in the total costs based on practice size and specialty. Total costs ranged from just under $\$ 34,000$ for a 2.5 -person pediatric practice to $>\$ 120,000$ for a pediatric practice with 10.5 FTE providers. Practices with 3.5 and 4 FTE providers had total costs estimates from just over $\$ 47,000$ (a pediatric practice) to nearly $\$ 64,000$ (the family medicine practice). The variation in costs based on the number of providers was driven by a combination of differences in how care management systems were operationalized, what types of supplies were purchased to meet requirements, and the time invested to understand how to generate required reports as well as other items displayed in Table 3.

Practice-level costs to support external consultants are shown in Table 4. Consultants or practice coaches provided 2 to 3 hours of on-site support each month to help practices identify necessary training materials and to guide and sequence the application processes, that ranged from approximately 9 to 18 months.
Table 4. Costs of External Consultants (Per Practice)

\begin{tabular}{ll}
\hline Practice 1 (Pediatrics) & $\$ 2700$ \\
\hline Practice 2 (Pediatrics) & $\$ 1050$ \\
Practice 3 (Pediatrics) & $\$ 2600$ \\
Practice 4 (Family medicine) & $\$ 750$ \\
\hline
\end{tabular}

Table 5 identifies the PCMH activities that required the most time $(T)$ and highlights those which were noted to be of high-value (superscript $V)$. The largest time investments were made to complete the application workbooks, draft new policies and job descriptions, take and format screenshots, and identify strategies to manage the population of patients with chronic conditions and preventive care needs. Of these activities, the work that practices did to (1) define populations in need of services, (2) reach consensus on evidence-based protocols to implement, (3) strategize on closing loops with referring providers and outstanding laboratory and imaging tests, and (4) engage patients and families were unanimously voiced as well worth the effort. These activities were described as truly transformative and most likely to help improve patient experiences and outcomes.

\section{Discussion}

This study of 4 primary care practices in North Carolina is one of the few we are aware of that used activity-based methods to describe the costs of applying for NCQA level 3 PCMH recognition. Results suggest that the cost per FTE provider may be similar across practices. Mean cost per provider in our study was $\$ 13,700$. This represents a significant opportunity cost for practices of any size-one that, without financial incentives or technical support, may hinder widespread adoption, despite the promise of the $\mathrm{PCMH}$ as a quality improvement strategy.

Emerging evidence of the effectiveness of the PCMH model indicates that transformation may improve care quality and outcomes; however, evidence of its effect on patient-level health care costs has been mixed. ${ }^{23-26}$ Importantly, studies suggest that if savings do emerge, they are likely to come from reductions in emergency department visits or hospitalizations ${ }^{23,25}$ and thus will not financially benefit primary care practices un- 


\begin{tabular}{|c|c|c|c|c|}
\hline & $\begin{array}{r}\text { Practice } 1 \\
\text { (Pediatrics) }\end{array}$ & $\begin{array}{r}\text { Practice } 2 \\
\text { (Pediatrics) }\end{array}$ & $\begin{array}{r}\text { Practice } 3 \\
\text { (Pediatrics) }\end{array}$ & $\begin{array}{l}\text { Practice } 1 \\
\text { (Family } \\
\text { Medicine) }\end{array}$ \\
\hline $\begin{array}{l}\text { Previsit planning and care coordination processes new work } \\
\text { to pre-populate patient charts, prepare for visits, identify } \\
\text { overdue or upcoming screening or other tests to } \\
\text { recommend) }\end{array}$ & $\mathrm{T}^{\mathrm{V}}$ & $\mathrm{T}^{\mathrm{V}}$ & & $\mathrm{T}^{\mathrm{V}}$ \\
\hline $\begin{array}{l}\text { Defining } 3 \text { preventive care services, } 3 \text { different chronic care } \\
\text { services and identifying patients not recently seen and } \\
\text { patients on specific medications }\end{array}$ & $\mathrm{T}^{\mathrm{V}}$ & $\mathrm{T}^{\mathrm{V}}$ & $T^{V}$ & $T^{V}$ \\
\hline $\begin{array}{l}\text { Writing office policies defining processes to define work } \\
\text { flows for following up on laboratory, imaging, } \\
\text { and other care processes including drafting agreements } \\
\text { with consultants; drafting job descriptions }\end{array}$ & $\mathrm{T}^{\mathrm{V}}$ & $\mathrm{T}^{\mathrm{V}}$ & $\mathrm{T}$ & $\mathrm{T}^{\mathrm{V}}$ \\
\hline $\begin{array}{l}\text { Demonstrating that }>50 \% \text { of patients who request an e-copy of } \\
\text { their information receive it within } 3 \text { business days }\end{array}$ & $\mathrm{T}$ & $\mathrm{T}$ & & \\
\hline Establish patient satisfaction survey process & $T^{V}$ & $T^{V}$ & $\mathrm{~T}$ & \\
\hline $\begin{array}{l}\text { Starting new office meetings dedicated to quality } \\
\text { improvement and working to complete NCQA } \\
\text { application requirements }\end{array}$ & & $\mathrm{T}$ & & $\mathrm{T}$ \\
\hline $\begin{array}{l}\text { Creating and processing screenshots to demonstrate } \\
\text { existence of required elements }\end{array}$ & $\mathrm{T}$ & $\mathrm{T}$ & $\mathrm{T}$ & $\mathrm{T}$ \\
\hline $\begin{array}{l}\text { Providing after-hours access to care (providing advice to } \\
\text { patients electronically, and via phone, demonstrating hat } \\
\text { afterhours advice is then incorporated into the patient } \\
\text { record) }\end{array}$ & $\mathrm{T}$ & $\mathrm{T}$ & & $\mathrm{T}$ \\
\hline Workbook preparation and documentation & $\mathrm{T}$ & $\mathrm{T}$ & $\mathrm{T}$ & $\mathrm{T}$ \\
\hline $\begin{array}{l}\text { Clinical advice via secure messages during office (via } \\
\text { establishment of a patient portal purchased for PCMH work) }\end{array}$ & & $\mathrm{T}$ & $\mathrm{T}$ & \\
\hline
\end{tabular}

*All activities required at least one full working day (8 hours) of staff time to complete. Many activities, especially regarding preparing policy documents, job descriptions, screenshots, documenting chart data into workbooks, and devising plans managing populations, took much longer than 8 hours.

NCQA, National Committee for Quality Assurance; PCMH, patient-centered medical home; T, greatest time investment; $\mathrm{T}^{\mathrm{V}}$, highest value for improving patient care.

less financial incentives or risk-based payment models are in place.

However, our participants acknowledged that several of the newly implemented activities were critical to improving care quality and were thankful that the application process drove their organizations to understand the need to dedicate time and resources to make these advancements. Of particular value were those activities that provided enhanced care management services to patients, that "closed loops," that supported the implementation of evidenced-based care protocols, and that engaged patients and families in improving the patient experience. However, the practices also were clear that the economic incentives from a dominant commercial insurer in North Carolina were critical to their decision to engage in this work.

Prior work detailing the investment that is required of practices to transform to medical homes suggests that smaller practices would find it particularly challenging because of having fewer resources to dedicate to these efforts. ${ }^{27,28}$ However, in our small sample of practices that received some consistent guidance from the North Carolina Area Health Education Center's Practice Support Program practice coaches, these challenges were able to be overcome. In fact, within our small sample we did not detect a marked cost advantage of being in progressively larger groups. Rather, differences in the effort required to meet various criteria were driven more by differences in patient population, or by practices' levels of engagement with previous quality improvement projects that overlapped the work required for PCMH recognition.

\section{Limitations}

We recognize that our study and results are limited to a small sample of 4 practices in North 
Carolina, with 3 of the 4 being pediatric practices, and that our findings cannot be generalized to other settings. Importantly, practices in our study had the opportunity to engage in incentive programs that helped to motivate their decision to transform. In addition, 2 of the 4 practices were independently run, but they were members of a practice network and thus had shared administrative personnel who provided some support for the PCMH application process. Our practices all aimed for level 3 recognition; thus we cannot comment on how costs may be different for practices looking for level 1 or 2 recognition.

We also understand that respondent recall bias may affect the accuracy of our cost estimates. Still, reported estimates of the time required to create screenshots and draft office policies were consistent across the sites. In addition, during some interviews, we were able to review meeting agendas that detailed the times and content of office quality improvement/PCMH meetings, which helped to mitigate recall issues. Another concern is that the level of information we asked for during a single interview could have affected respondent energy and biased estimates accordingly. In future studies, staggering data collection throughout the application process could help to reduce both recall bias and fatigue.

Finally, much of the PCMH application work, especially by the providers, occurred outside of time during which they would otherwise be generating clinical revenue. The majority of our costs are thus "opportunity costs" that do not directly affect practice finances. Still, the investment of time and resources is not insignificant. Last, we did not gather information on benefits packages for the involved staff; one needs to include such calculations to generate total employee costs.

\section{Recommendations to Reduce the Burden on Practices When Applying for PCMH Recognition}

To encourage broader implementation of the PCMH model, NCQA and other organizations could consider providing additional resources to enable practices to spend less time on some of the high-burden activities that are not viewed as creating value for patients. For instance, providing access to resources to facilitate preparation of the required screenshots could help reduce the costs to practices. Software such as the popular "Figure 1" for medical imaging sharing provides a number of tools to efficiently remove patient identifiers from photographs and other images, ${ }^{29}$ and could help to increase the efficiency of redacting protected information.

Similarly, NCQA and other organizations could reduce the amount of time practices spend drafting job descriptions and policies by having modifiable templates available online. Experienced practice coaches and practice staff who have created such documents could identify and share such examples.

\section{Conclusions}

The experience of 4 primary care practices in North Carolina suggests that the benefits of developing and implementing the processes required to receive level 3 PCMH recognition from NCQA are well worth the effort. However, successful transformation requires significant investments of personnel time and resources, and these costs cannot be ignored.

As investigators continue to examine the effects of the PCMH model on patient-level outcomes and costs, they should also explore ways to incorporate practice-level costs. This study has demonstrated the feasibility of using activitybased approaches to understand these costs; however, more work remains to develop reliable and valid instruments that can be used across a variety of practice settings. Work is currently underway to develop, validate, and disseminate such instruments within the developing field of implementation science. ${ }^{30,31}$ As health care organizations continue to strive to achieve the Institute for Healthcare Improvement's triple aim, these instruments will be critical to the rigorous evaluation of the sustainability of innovations and emerging interventions.

The authors are indebted to practices that are part of the North Carolina Network Consortium for their continued interest and participation in research and quality improvement.

\section{References}

1. Nielson M, Grundy P, Langner B, Zeemer, C. Benefits of implementing the primary care patient centered medical home: a review of cost \& quality results, 2012. Available from: https:/www.pcpcc.org/guide/benefitsimplementing-primary-care-medical-home. Accessed November 21, 2015. 
2. Patel MS, Arron MJ, Sinsky TA, et al. Estimating the staffing infrastructure for a patient-centered medical home. Am J Manag Care 2013;19: 509-16.

3. Paulus RA, Davis K, Steele GD. Continuous innovation in health care: implications of the Geisinger experience. Health Aff (Millwood) 2008;27: $1235-45$.

4. Steele GD, Haynes JA, Davis DE, et al. How Geisinger's advanced medical home model argues the case for rapid-cycle innovation. Health Aff (Millwood) 2010;29:2047-53.

5. Fields D, Leshen E, Patel K. Analysis \& commentary. Driving quality gains and cost savings through adoption of medical homes. Health Aff (Millwood) 2010;29:819-26.

6. Murray M, Davies M, Boushon B. Panel size: how many patients can one doctor manage? Fam Pract Manag 2007;14:44-51.

7. Mehrotra A, Keehl-Markowitz L, Ayanian JZ. Implementing open-access scheduling of visits in primary care practices: a cautionary tale. Ann Intern Med 2008;148:915-22.

8. Philis-Tsimikas A, Fortmann A, Lleva-Ocana L, Walker C, Gallo LC. Peer-led diabetes education programs in high-risk Mexican Americans improve glycemic control compared with standard approaches: a Project Dulce promotora randomized trial. Diabetes Care 2011;34:1926-31.

9. Ghorob A, Vivas MM, De Vore D, et al. The effectiveness of peer health coaching in improving glycemic control among low-income patients with diabetes: protocol for a randomized controlled trial. BMC Public Health 2011;11:208.

10. Barg FK, Weiner MG, Joseph S, Pandit K, Turner BJ. Qualitative analysis of peer coaches' experiences with counseling African Americans about reducing heart disease risk. J Gen Intern Med 2012;27:167-72.

11. Spencer MS, Rosland AM, Kieffer EC, et al. Effectiveness of a community health worker intervention among African American and Latino adults with type 2 diabetes: a randomized controlled trial. An J Public Health 2011;101:2253-60.

12. Kumanyika SK, Fassbender JE, Sarwer DB, et al. One-year results of the Think Health! study of weight management in primary care practices. Obesity 2012;20:1249-57.

13. Crabtree BF, Nutting PA, Miller WL, Stange KC, Stewart EE, Jaen CR. Summary of the National Demonstration Project and recommendations for the patient-centered medical home. Ann Fam Med 2010;8(Suppl 1):S80-90; S92.

14. Nutting PA, Miller WL, Crabtree BF, Jaen CR, Stewart EE, Stange KC. Initial lessons from the first national demonstration project on practice transformation to a patient-centered medical home. Ann Fam Med 2009;7:254-60.
15. Scholle SH, Saunders RC, Tirodkar MA, Torda P, Pawlson LG. Patient-centered medical homes in the United States. J Ambul Care Manage 2011;34: 20-32.

16. Reiter KL, Halladay JR, Mitchell CM, et al. Costs and benefits of transforming primary care practices: a qualitative study of North Carolina's Improving Performance in Practice. J Healthc Manag 2014;59:95-108.

17. Paustian ML, Alexander JA, El Reda DK, Wise CG, Green LA, Fetters MD. Partial and incremental PCMH practice transformation: implications for quality and costs. Health Serv Res 2014; 49:52-74.

18. Donahue KE, Halladay JR, Wise A, et al. Facilitators of transforming primary care: a look under the hood at practice leadership. Ann Fam Med May-Jun 11 Suppl 1:S27-33, 2013.

19. Halladay JR, Dewalt DA, Wise A, et al. More extensive implementation of the chronic care model is associated with better lipid control in diabetes. J Am Board Fam Med 2014;27:34-41.

20. NCQA. NCQA PCMH 2011 Standards, Elements and Factors Documentation Guideline/Data Sources. https://www.ncqa.org/Portals/0/Programs/ Recognition/PCMH_2011_Data_Sources_6.6.12. Published 6/6/2012. Accessed Aug 17, 2015.

21. May 2012 national occupational employment and wage estimates United States. Last modified November 27, 2013. Washington, DC: US Bureau of Labor Statistics. Available from: http://www.bls.gov/ oes/2012/may/oes_nat.htm\#29-0000. Accessed November 21, 2015.

22. Medical Group Management Association [homepage]. Available from: http://www.mgma.com/. Accessed May 30, 2015.

23. Romaire MA, Bell JF, Grossman DC. Health care use and expenditures associated with access to the medical home for children and youth. Med Care 2012;50:262-9.

24. Koshy RA, Conrad DA, Grembowski D. Lessons from Washington state's medical home payment pilot: what it will take to change American health care. Popul Health Manag 2015;18:237-45.

25. van Hasselt M, McCall N, Keyes V, Wensky SG, Smith KW. Total cost of care lower among Medicare fee-for-service beneficiaries receiving care from patient-centered medical homes. Health Serv Res 2015;50:253-72.

26. Alexander JA, Markowitz AR, Paustian ML, et al. Implementation of patient-centered medical homes in adult primary care practices. Med Care Res Rev 2015;72:438-67.

27. Landon BE, Normand SL. Performance measurement in the small office practice: challenges and potential solutions. Ann Intern Med 2008;148:353-7.

28. Berry CA, Mijanovich T, Albert S, et al. Patientcentered medical home among small urban prac- 
tices serving low-income and disadvantaged patients. Ann Fam Med 2013;11(Suppl 1):S82-9.

29. Figure 1. Frequently asked questions. Available from: https://figure1.com/sections/faq/. Accessed May 30, 2015.

30. Lewis CC, Stanick CF, Martinez RG, et al. The Society for Implementation Research Collaboration Instru- ment Review Project: a methodology to promote rigorous evaluation. Implement Sci 2015;10:2.

31. Lewis CC, Fischer S, Weiner BJ, Stanick C, Kim M, Martinez RG. Outcomes for implementation science: an enhanced systematic review of instruments using evidence-based rating criteria. Implement Sci 2015;10:155. 